\title{
Estimation of loss caused by earthquakes and secondary technological hazards
}

\author{
N. I. Frolova ${ }^{1}$, V. I. Larionov ${ }^{2}$, S. P. Suschev ${ }^{2}$, and J. Bonnin ${ }^{3}$ \\ ${ }^{1}$ Seismological Center of IGE, Russian Academy of Sciences, Moscow, Russia \\ ${ }^{2}$ Moscow High Technical University named after Bauman, Moscow, Russia \\ ${ }^{3}$ Institute of Physics of the Earth, University of Strasbourg, France
}

Received: 17 June 2011 - Revised: 16 September 2011 - Accepted: 28 September 2011 - Published: 14 November 2011

\begin{abstract}
Assessment of expected loss and damage caused by earthquakes and secondary technological accidents are of primary importance for the development and implementation of preventive measure plans, as well as for emergency management just after the disaster. The paper addresses the procedures for estimations of loss caused by strong events and secondary hazards with information technology application. Examples of individual seismic risk zoning at Russian federal and regional levels are given, as well as that of scenario earthquakes consequences estimation, taking into account secondary technological hazards.
\end{abstract}

\section{Introduction}

Earthquakes are becoming more devastating, especially when they occur in industrialized regions. Social and economic losses due to those events and secondary processes triggered by them, increase annually, which is definitely in relation with the evolution of society. Seismic and secondary technological hazards identification and analysis, as well as risk assessment and mapping, are the first steps in prevention strategy aimed at saving lives and protecting property against future events. The paper addresses methodological issues of risk assessment and mapping taking into account technological accidents at fire, explosion and chemical hazardous facilities triggered by strong seismic events. Special GIS environments are usually developed for risk assessment and mapping at different levels. Examples of individual seismic risk zoning for the population of the Russian Federation and for the Krasnodar region are given, as well as that

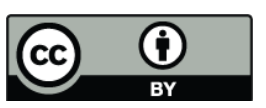

Correspondence to: N. I. Frolova (frolova@esrc.ru) of scenario earthquakes consequences estimation taking into account secondary technological hazards at urban and facility levels.

\section{The methodological issues of risk assessment}

The section describes the procedures for individual risk assessment created by earthquakes and seismic risk assessment taking into account secondary technological accidents. For estimation of risk indexes and risk mapping, the probabilistic approach is used.

For seismic risk assessment the authors follow the concepts proposed and agreed upon by UN and other experts in the field (Karnik et al., 1978; Fournier d'Albe, 1982, 1986; Karnik, 1984; Boissonnade and Shah, 1984; Mitigating, 1991; Dolce et al., 1995; UNISDR, 2009; Risk, 2010; Ranguelov, 2011).

Individual risk $R_{\mathrm{e}}$ due to any hazard is determined as the probability of death and/or injuries and/or economic loss for persons due to potential hazard within one year at a given place. Individual seismic risk $R_{\mathrm{s}}$ is the product of hazard $H$ and vulnerability $V_{\mathrm{s}}$. Vulnerability of the population to seismic action of a given intensity is understood here as the ratio between the number of persons expected to be affected by fatalities, injuries, losses of property and the total number of persons living in a certain type of buildings (Larionov and Frolova, 2003a). Individual seismic risk $R_{\mathrm{s}}$ (Bonnin et al., 2002; Bonnin and Frolova, 2004; Frolova et al., 2003, 2011; Larionov et al., 2003b; Methods, 2000) may be determined through mathematical expectation of social losses, which include fatalities, injuries and persons who lost their property, $M(N)$, taking into account the number of inhabitants $N$ in the considered settlement and probability of seismic event $H$

Published by Copernicus Publications on behalf of the European Geosciences Union. 
Table 1. Comparison of building vulnerability classes according to MMSK-86 and EMS-98.

\begin{tabular}{lcc}
\hline Description of buildings' types according to EMS-98 & \multicolumn{2}{c}{ Vulnerability class } \\
\cline { 2 - 3 } & EMS-98 & MMSK-86 \\
\hline Rubble stone, field stone & A & A \\
Adobe (earth brick) & A & A \\
Simple stone & B & A \\
Massive stone & C & Б \\
Unreinforced (bricks/concrete blocks) & B & 5 \\
Unreinforced (brick) with RC floors & C & B \\
Reinforced or confined & D & 5 \\
Reinforced without earthquake-resistant design (ERD) & C & 5 \\
Reinforced with minimum level of ERD & D & C7 \\
Reinforced with average level of ERD & E & C8 \\
Reinforced with high level of ERD & F & C9 \\
Timber structures & D & B-C7 \\
\hline
\end{tabular}

$R_{\mathrm{S}}=H \times V_{\mathrm{S}}(I)=H \times M(N) / N$

where $-V_{\mathrm{s}}(I)$ is the vulnerability of population in the considered settlement; $-H$ is the probability of seismic event occurrence per one year; $-N$ is the number of inhabitants in the considered settlement.

The mathematical expectation of social losses $M\left(N_{j}\right)$ in certain $j$-type buildings for the considered settlement, taking into account inhabitant migration in the buildings of $j$-type during the day and night, is determined by equation

$$
\begin{aligned}
M\left(N_{j}\right)= & f(t) \iint_{S_{c}} \int_{I_{\min }}^{I_{\max }} P_{C_{j}}(I) \times f(x, y, I) \\
& \times \Psi_{j}(x, y) \times d I d x d y
\end{aligned}
$$

where $-I_{\min }$ and $I_{\max }$ are the maximum and minimum possible seismic intensities; $S_{\mathrm{c}}$ is the settlement area; $P_{C j}(I)$ is the probability of fatalities, injuries and persons having lost their property, under the condition of damage to buildings of $j$-type due to an earthquake with intensity $I ; \psi_{j}(x, y)$ is the density of population distribution within the considered area in buildings of $j$-type; $f(x, y, I)$ is the density function of earthquakes' intensity probabilities within the unit area with coordinates $x, y ; f(t)$ is the function obtained on the basis of statistical analysis of data on the population migration over $24 \mathrm{~h}$.

Computations of $P_{C j}(I)$ are carried out using equation

$P_{C j}(I)=\sum_{i=1}^{5} P_{B i}(I) \times P\left(C_{j} \mid B_{i}\right)$

where $-P_{C j}(I)$ is the probability of people being impacted on during the earthquake of intensity $I ;-P_{B i}(I)$ is the probability of definite damage state $i$ of buildings under the action of seismic load with intensity $I ;-P\left(C_{j} \mid B_{i}\right)$ is the probability of people to survive $j$ level of impact under the condition that the building survived the damage state $i$ (five damage states are considered here, from $i=1$ (slight damage) to $i=5$ (total collapse)).

The computations of $P_{C j}(I)$ are usually done for building and structure types classified according to the MMSK-86 scale (Shebalin et al., 1986): buildings' type A (from local materials); buildings' type B (brick, hewn stone or concrete blocks); buildings' type C (reinforced concrete, frame, large panels and wood); buildings' types E7, E8, E9 (earthquake resistant which are designed and constructed to withstand earthquakes with intensity 7, 8, 9). MMSK-86 and EMS-98 originate from MSK-64 and the expert estimation of different building types according to MMSK- 86 and EMS-98 was undertaken (Table 1) in order to have the possibility of comparison of different vulnerability functions.

The mathematical expectation of social losses $M(N)$ due to earthquakes in damaged and collapsed buildings for the considered settlement, taking into account inhabitant migration in the buildings of all types during the day and night, is determined by equation

$M(N)=\sum_{j=1}^{n} M\left(N_{j}\right)$

where $-n$ is the number of considered building types according to the MMSK- 86 scale.

Secondary consequences resulting from technological accidents (fires, explosions, release of chemical materials) triggered by earthquakes, are estimated in a few steps: (1) Critical facilities with storage of different hazardous materials (fire, explosion and chemical hazardous substances) are identified; (2) distribution of shaking intensity is simulated for given parameters of scenario earthquake; (3) field of impact factors, such as excessive pressure, combustion temperature, 
concentration of chemical hazardous materials, are constructed taking into account wind direction, air temperature and pressure, wind velocity and others factors; (4) probability is estimated that the critical facility will survive the damage state above threshold value; (5) social loss and individual risk are estimated in the case of technological accidents triggered by earthquake, according to Eqs. (5) and (6).

Individual risk $R_{\mathrm{ei}}$ in the case of an accident at fire and explosion hazardous facilities (Methods, 2002) is determined by

$$
\begin{aligned}
R_{\mathrm{ei}}= & \frac{1}{N} \sum_{k} H_{k} \sum_{j} \iint_{S} E_{k j}(x, y) \times P_{j}(x, y) \\
& \times \psi(x, y) \times d x \times d y .
\end{aligned}
$$

where $-H_{k}$ is the probability of accident per year according to scenario $k$ (fires, fire balls, explosions and other phenomena may be considered as scenario events); $E_{k j}(x, y)$ is the probability of impact mechanism $j$ in the point $(x, y)$ for the accident scenario $k$ (as an impact mechanism, the following factors could be considered: heat effect on population, shock wave, debris of buildings and constructions, and others); $P_{j}(x, y)$ is the probability of fatality in the point with coordinates $(x, y)$ under the condition that impact mechanism $j$ is realized; $\psi(x, y)$ is the density of population distribution in the vicinity of the point with coordinates $(x, y)$; $N$ is the number of people within the zone of risk; $S$ is the area within which people may be impacted in the case of an accident (i.e. the zone of risk).

Individual risk $R_{\mathrm{ei}}$ in the case of an accident at a chemical hazardous facility (Methods, 2002) is determined by

$$
\begin{aligned}
R_{\mathrm{ei}}= & \frac{H}{N} \iint_{S} \int_{0}^{2 \pi} \int_{V_{\min }}^{V_{\max }} f(a, V) \times P[Д(x, y)] \times \psi(x, y) \\
& \times d V \times d a \times d x \times d y,
\end{aligned}
$$

where $-H$ is the probability of an accident per year; $N$ is the number of inhabitants; $S$ is the area within which the people may be impacted in the case of an accident at a given facility; $\pi=3.14 ; V_{\min }$ and $V_{\max }$ are minimum and maximum possible values of wind velocity; $f(a, V)$ is the density function of probability of wind direction $a$ and wind velocity $V ; \psi(x, y)$ is the density of the population distribution in the vicinity of the point with coordinates $(x, y) ; P\left[Д_{(x, y)}\right]$ is the probability of the population to be impacted by toxic dose in the point with coordinates $(x, y) ; Д_{(x, y)}$ is the toxic dose, which is determined under time-dependent concentration of chemical hazardous material at a point with coordinates $(x, y)$ by equation

Д $(x, y)=\int_{t_{n}}^{t_{k}} \Omega(x, y, t) \times d t$,

where $-t_{n} \ldots t_{k}$ is the time interval within which the concentration of the chemical substance is dangerous; $\Omega(x, y, t)$ is the concentration of the chemical hazardous substance in the atmosphere at the point with coordinates $(x, y)$.

Integrated individual risk $R_{\mathrm{e}}(x, y)$ due to earthquakes and secondary technological accidents (Methods, 2000, 2002; Frolova et al., 2007) is determined by equation

$R_{e}(x, y)=1-\prod_{i=1}^{n}\left[1-R_{\mathrm{ei}}(x, y)\right]$

where $-n$ is the number of considered emergencies; $R_{\mathrm{ei}}(x, y)$ is the individual risk due to $i$-th emergency situation.

\section{Seismic risk assessment at different levels}

Earthquakes are the most hazardous natural processes in the Russian Federation, which may result in fatalities, injuries and economic loss. The results of seismic risk assessment taking into account secondary hazards are essential (practical) input for planning and implementing preventive measures at national and local authority levels, as well as actions to be taken by the Ministry of the Russian Federation for Civil Defense, Emergencies and Elimination of Consequences of Natural Disasters (EMERCOM of Russia) just after the occurrence of a strong earthquake. Taking into account the fact that at present, in Russia, existing and underconstruction oil pipe routes cross the earthquake prone areas with high level of seismicity, the above-described procedure is used for risk assessment regarding possible damage to facilities of TRANSNEFT JSC; the corresponding GIS environment is further developed. Examples of risk estimations and mapping at different scales are given below.

\subsection{Seismic risk assessment and mapping at federal level}

The procedure described above was used for the computation of individual risk for the territory of the Russian Federation with application of special GIS environment. Values of seismic risk obtained for separate cities and settlements were averaged within the administrative divisions of the country. Three maps of individual seismic risk were constructed: $R_{\mathrm{S}} 1$ - probability of fatalities; $R_{\mathrm{S}} 2$ - probability of fatalities and injuries; $R_{\mathrm{S}} 3$ - probability of fatalities, injuries and economic loss for population due to the occurrence of earthquakes within one year. Figure 1 shows the map of individual seismic risk zoning $R_{\mathrm{S}} 1$ (probability of fatalities). Values obtained for individual seismic risk vary from negligible, close to zero, up to rather high values: more than $30 \times 10^{-5}$ for the probability of fatalities (map $R_{\mathrm{S}} 1$ ); more than $100 \times 10^{-5}$ for the probability of fatalities and injuries (map $R_{\mathrm{S}} 2$ ); more than $150 \times 10^{-5}$ for the probability of fatalities, injuries and economic loss to population caused by earthquakes per year (map $R_{\mathrm{S}} 3$ ). Table 2 shows the extent of zones with different levels of individual seismic risk according to maps $R_{\mathrm{S}} 1, R_{\mathrm{s}} 2$ and $R_{\mathrm{s}} 3$. 
Table 2. Values of individual seismic risk and extent of zones with different risk levels.

\begin{tabular}{|c|c|c|c|c|c|c|c|}
\hline \multirow{2}{*}{$\begin{array}{l}\text { Risk ranges } \\
10^{-5} \mathrm{yr}^{-1}\end{array}$} & \multirow{2}{*}{$\begin{array}{l}\text { Qualitative risk } \\
\text { characteristics }\end{array}$} & \multicolumn{2}{|c|}{$\begin{array}{l}\text { Extent of zones, } \\
\text { map } R_{\mathrm{S}} 1\end{array}$} & \multicolumn{2}{|c|}{$\begin{array}{l}\text { Extent of zones, } \\
\text { map } R_{\mathrm{S}} 2\end{array}$} & \multicolumn{2}{|c|}{$\begin{array}{c}\text { Extent of zones, } \\
\text { map } R_{\mathrm{S}} 3\end{array}$} \\
\hline & & $10^{6} \mathrm{~km}^{2}$ & $\%$ & $10^{6} \mathrm{~km}^{2}$ & $\%$ & $10^{6} \mathrm{~km}^{2}$ & $\%$ \\
\hline$<0.1$ & small & 8.8 & 53 & 8.1 & 49 & 7.6 & 46 \\
\hline $0.1-1.0$ & moderate & 2.5 & 15 & 2.9 & 17 & 2.2 & 13 \\
\hline $1.0-5.0$ & average & 2.4 & 14 & 1.5 & 9 & 1.9 & 11 \\
\hline $5.0-10.0$ & high & 1.2 & 7 & 1.4 & 8 & 0.9 & 5 \\
\hline $10.0-30.0$ & rather high & 1.2 & 7 & 1.5 & 9 & 1.8 & 11 \\
\hline $30.0-100.0$ & & 0.5 & 3 & 1.1 & 7 & 1.6 & 10 \\
\hline $100.0-150.0$ & extremely high & - & - & 0.1 & 1 & 0.2 & 1 \\
\hline$>150.0$ & & - & - & - & - & 0.4 & 2 \\
\hline
\end{tabular}

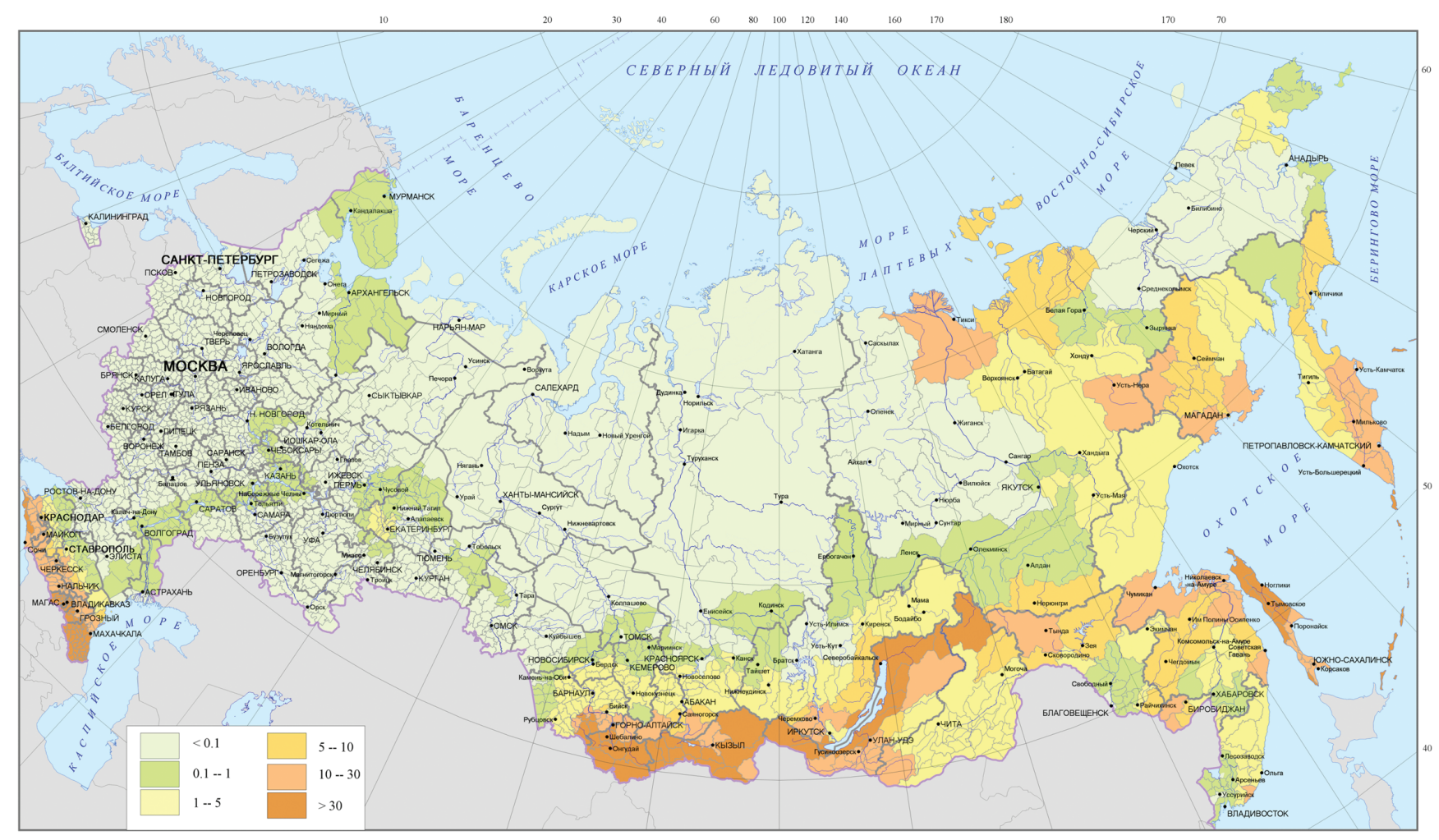

Fig. 1. Map of individual seismic risk $R_{\mathrm{S}} 1,10^{-5} \mathrm{yr}^{-1}$, for the territory of the Russian Federation.

The computed values of individual seismic risk $R_{\mathrm{S}} 1$ are more than $30 \times 10^{-5} \mathrm{yr}^{-1}$ for all administrative divisions within the Sakhalin area, Republic of Altay, Tuva, Dagestan and Northern Osetia. The highest values of individual seismic risk $R_{\mathrm{S}} 3$ are obtained for Kamchatka, near lake Baikal, Republic of Buryatia, Irkutsk region, Altay kray, as well as for the Krasnodar region and Chechen Republic.

\subsection{Seismic risk assessment and mapping at regional level}

The Krasnodar region is characterised by a high density population and a rather high level of seismic hazard. According to maps of review seismic zoning of the Russian Federation territory, earthquakes with intensities $I=6-10$ according to the MMSK-86 scale may occur here. The loss computations for this region were done taking into account secondary man-made accidents at fire, explosion and chemical 


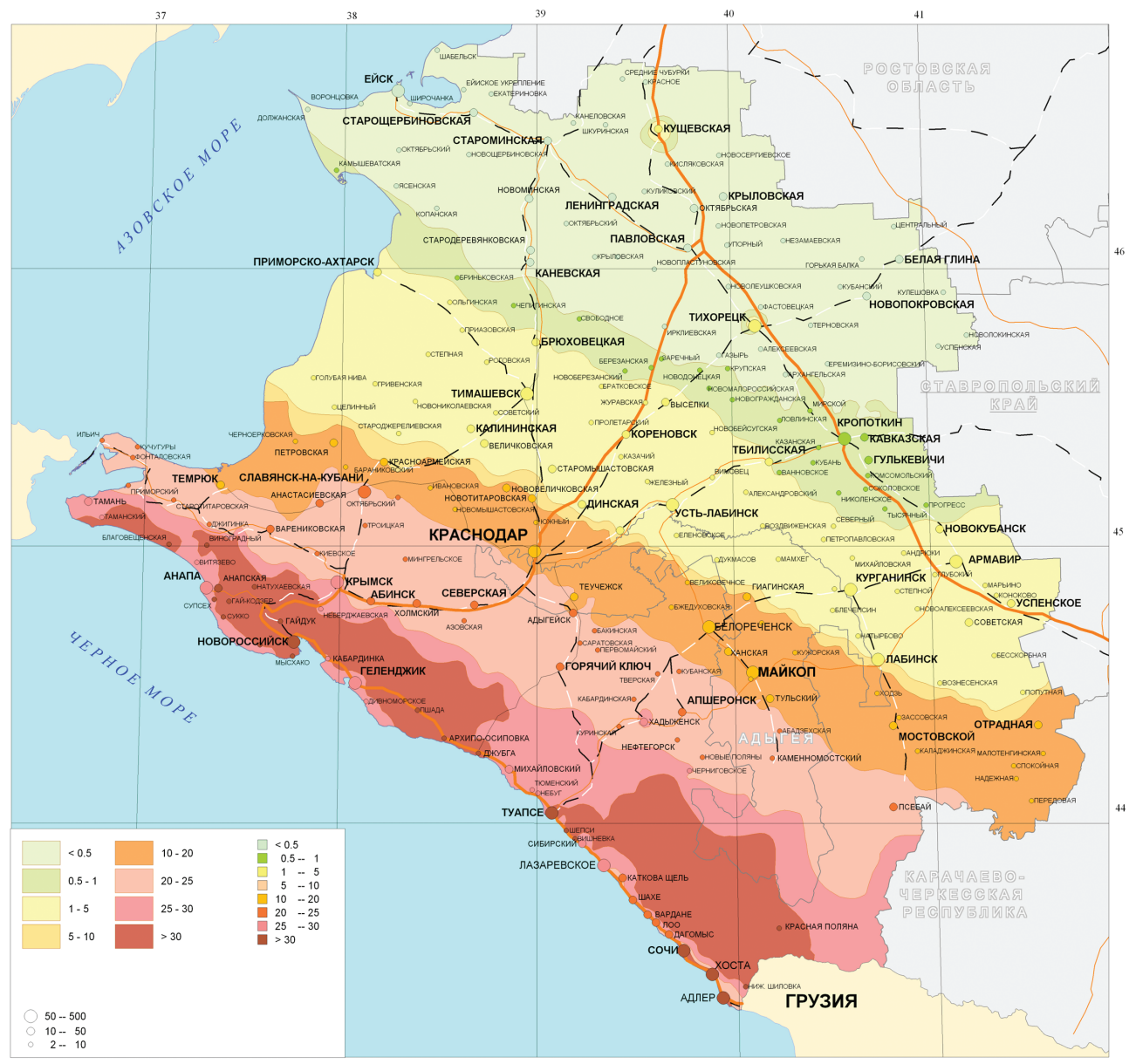

Fig. 2. Map of seismic risk $R_{\mathrm{st}} 1,10^{-5} \mathrm{yr}^{-1}$ zoning for the territory of the Krasnodar region, taking into account technological accidents triggered by earthquakes.

hazardous facilities. For risk assessment and mapping at a regional scale, information about the population and building stock distribution in the region was updated. The detailed inventory data obtained during the last years and data on the built environment provided by the Regional Departments of EMERCOM of Russian Federation, was used to develop the building stock models for 83 settlements with a population more than 10000 inhabitants, 281 ones with a population from 2000 up to 10000 inhabitants and 1647 rural settlements with the number of inhabitants less than 2000 persons each. The models are characterised by the percentage of buildings of different types according to the MMSK- 86 scale and their height. The parameters of regional vulnerability functions for different building types, as well as vulnerability functions for population, were checked for the Krasnodar region.

Estimation of individual risk for the population of the Krasnodar region was carried out for the worst scenarios when earthquakes occurred during the night time. In order to estimate expected social losses within cities and towns, they were divided into unit sites. Then indexes obtained for each unit site were summed up. The regional map of risk zoning (Fig. 2) includes two elements: risk for settlements with the number of inhabitants less than 1000, shown by "hypsometric" contours, and risk for settlements with the number of inhabitants more than 1000 shown by symbols (circles of different sizes and colours). The "hypsometric" scale is used to represent both elements on the map.

Values of risk obtained for the Krasnodar region (Fig. 2) vary from negligible values up to rather high ones equal to $30.0 \times 10^{-5}$. On the whole, for more that $60 \%$ of the Krasnodar region territory, the values of seismic risk computed taking into account the secondary technological accidents exceed the value of $1.0 \times 10^{-5}$ (Table 3). High level of individual seismic risk results from relatively high seismic activity of the area under consideration, lack of proper earthquake resistant measures for the existing building stock, as well as the presence of fire, explosion and chemical hazardous facilities in the settlements' territory.

Comparison of seismic risk values $R_{\mathrm{S}} 1$ averaged for administrative divisions of the Krasnodar area (Fig. 1), which were obtained at federal level, with risk values $R_{\mathrm{st}} 1$ (Fig. 2) 


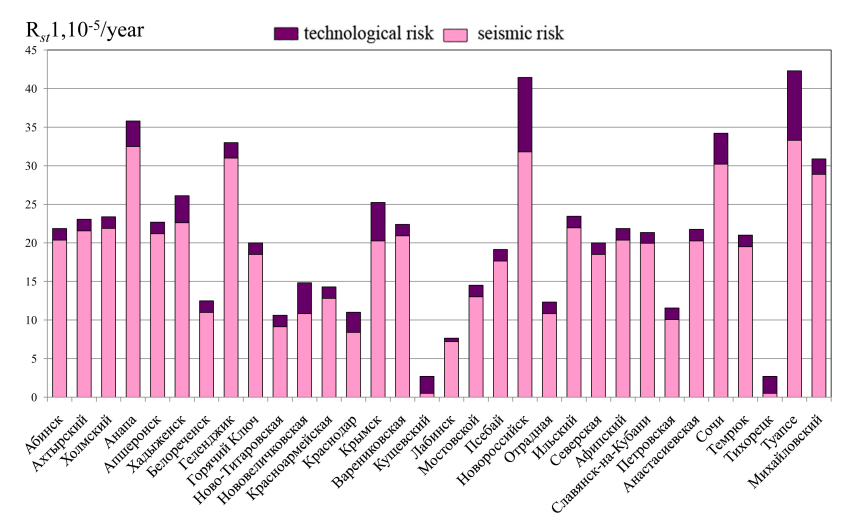

Fig. 3. Distribution of seismic risk $R_{\mathrm{st}} 1$, taking into account secondary technological accidents triggered by earthquakes for the settlements of the Krasnodar region.

Table 3. Extent of zones with different risk levels for the Krasnodar area.

\begin{tabular}{lll}
\hline Number & $\begin{array}{l}\text { Risk ranges, } \\
10^{-5} \mathrm{yr}^{-1}\end{array}$ & $\begin{array}{l}\text { Extent of } \\
\text { zones, } \mathrm{km}^{2}\end{array}$ \\
\hline 1 & $<0.5$ & 19651 \\
2 & $0.5 \times 10^{-5} \ldots 1.0$ & 5920 \\
3 & $1.0 \ldots 5.0$ & 18334 \\
4 & $5.0 \ldots 10.0$ & 1681 \\
5 & $10.0 \ldots 15.0$ & 8944 \\
6 & $15.0 \ldots 20.0$ & 2110 \\
7 & $20.0 \ldots 25.0$ & 12802 \\
8 & $25.0 \ldots 30.0$ & 6331 \\
9 & $>30.0$ & 7456 \\
\hline
\end{tabular}

for separate settlements of the Krasnodar area, which were obtained at regional level, allows us to draw the conclusion that average contribution of secondary technological accidents to the seismic risk is $10-15 \%$. The largest contribution of possible accidents triggered by earthquakes, equal to 20 $25 \%$, is obtained for cities Novorossijsk and Tuapse. Here the contribution of technological risk (Fig. 3 - dark colour) is connected mainly with the oil pipe facilities.

\subsection{Scenario earthquake consequences}

The Stavropol region is also characterised by a high density of population and a rather high level of seismic hazard. According to maps of review seismic zoning of the Russian Federation territory, earthquakes with intensities $I=6-9$ according to the MMSK-86 scale may occur in the region. The expected loss computations due to scenario events were done for the Stavropol area taking into account possible earthquake source zones (Fig. 4). The parameters of scenario earthquakes are shown in Table 4.
Table 4. Parameters of scenario earthquakes for the most hazardous source zones.

\begin{tabular}{lcccc}
\hline $\begin{array}{l}\text { No. of event, } \\
\text { see Fig. } 4\end{array}$ & $\begin{array}{l}\text { Coordinates } \\
\text { of epicentre }\end{array}$ & $\begin{array}{c}\text { Depth of } \\
\text { source, km }\end{array}$ & $M$ \\
\cline { 2 - 3 } & $\varphi^{0} \mathrm{~N}$ & $\lambda^{0} \mathrm{E}$ & & \\
\hline No. 1 & 43.75 & 43.08 & 20 & 7 \\
No. 2 & 43.92 & 42.49 & 15 & 6 \\
No. 3 & 43.98 & 43.22 & 15 & 6 \\
No. 4 & 43.71 & 42.44 & 20 & 7 \\
No. 5 & 44.98 & 41.97 & 10 & 5 \\
\hline
\end{tabular}

Expected damage to the building environment and human casualties were estimated for the worst scenarios under the condition that $95 \%$ of the population is inside buildings. Computations were carried out with special GIS code, which was developed for the region under consideration.

The most severe damage to building stock was obtained for events no. 1 and no. 4 (Table 4) with magnitude $M=7$ and source depth $h=20 \mathrm{~km}$. In the majority of cities and settlements located within a radius of $30-40 \mathrm{~km}$ from the epicentres of events no. 1 (Fig. 5) and no. 4 the buildings and constructions may survive an average damage state of $d=4$ (partial collapse), and within a radius of $50-100 \mathrm{~km}$ the average damage state $d$ may be equal to 3 (heavy damage). Within the settlements, separate buildings of different types, classified according to MMSK-86, may undergo damage state from $d=5$ (total collapse) up to slight damage $d=1$, depending on their seismic vulnerability and distance from the epicentre. Table 5 lists the results of expected damage computations for large settlements in the Stavropol area for scenario events no. 1 and no. 4.

In the case of scenario events no. 2 and no. 3 (Table 4) with magnitude $M=6$ and source depth $h=15 \mathrm{~km}$, the built environment in the majority of settlements may undergo in average slight damage $(d=1)$. The effect from such events may be felt in 400 settlements of the Stavropol area.

Macroseismic effect from scenario event no. 5, with a magnitude $M=5$ and source depth $h=10 \mathrm{~km}$ (Table 4) may reach $I_{0}=6-7$ (MMSK-86 scale) in the epicentre area. The building stock in average may undergo slight damage $(d=1)$. Such an earthquake may be felt in 99 settlements of the Stavropol area. In Stavropol City located $5 \mathrm{~km}$ from the epicentre of the scenario event, the seismic intensity may reach $I=6.5-7$ (MMSK-86 scale). In this city about $30 \%$ of buildings may undergo moderate damage $(d=2)$, about $20 \%$ - heavy damage $(d=3)$ and about $2 \%$ - partial collapse $(d=4)$.

When estimating scenario event consequences at urban and facility levels, the damage and loss resulting from secondary accidents triggered by earthquakes is also taken into account. Figure 6 shows the results of possible consequences simulation of chemical hazmat release at industrial facility. 


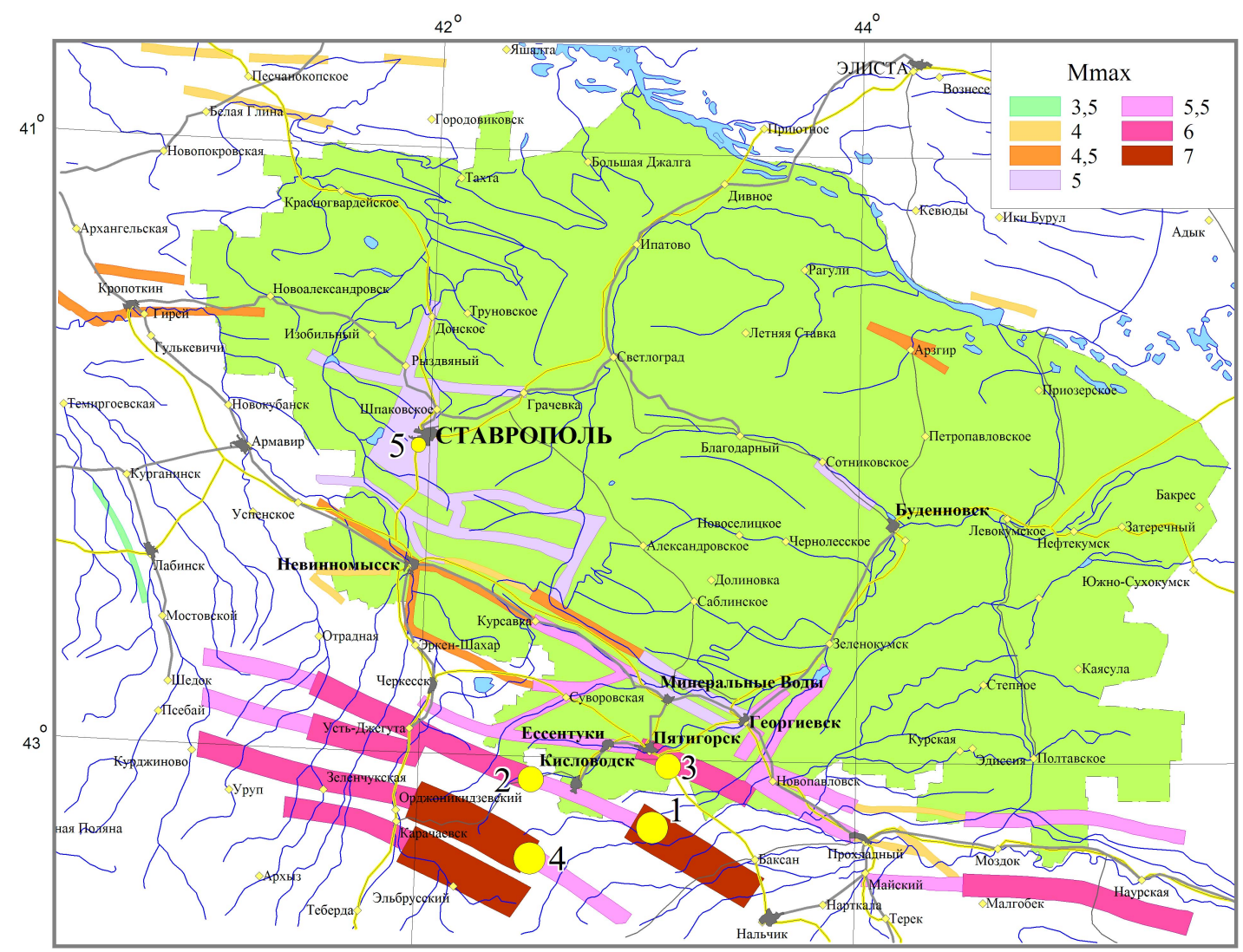

Fig. 4. Map of possible source zones for Stavropol region, according to Sobolev et al. (1996); numbered circles 1, 2, 3, 4 and 5 are scenario events' epicentres (Table 4).

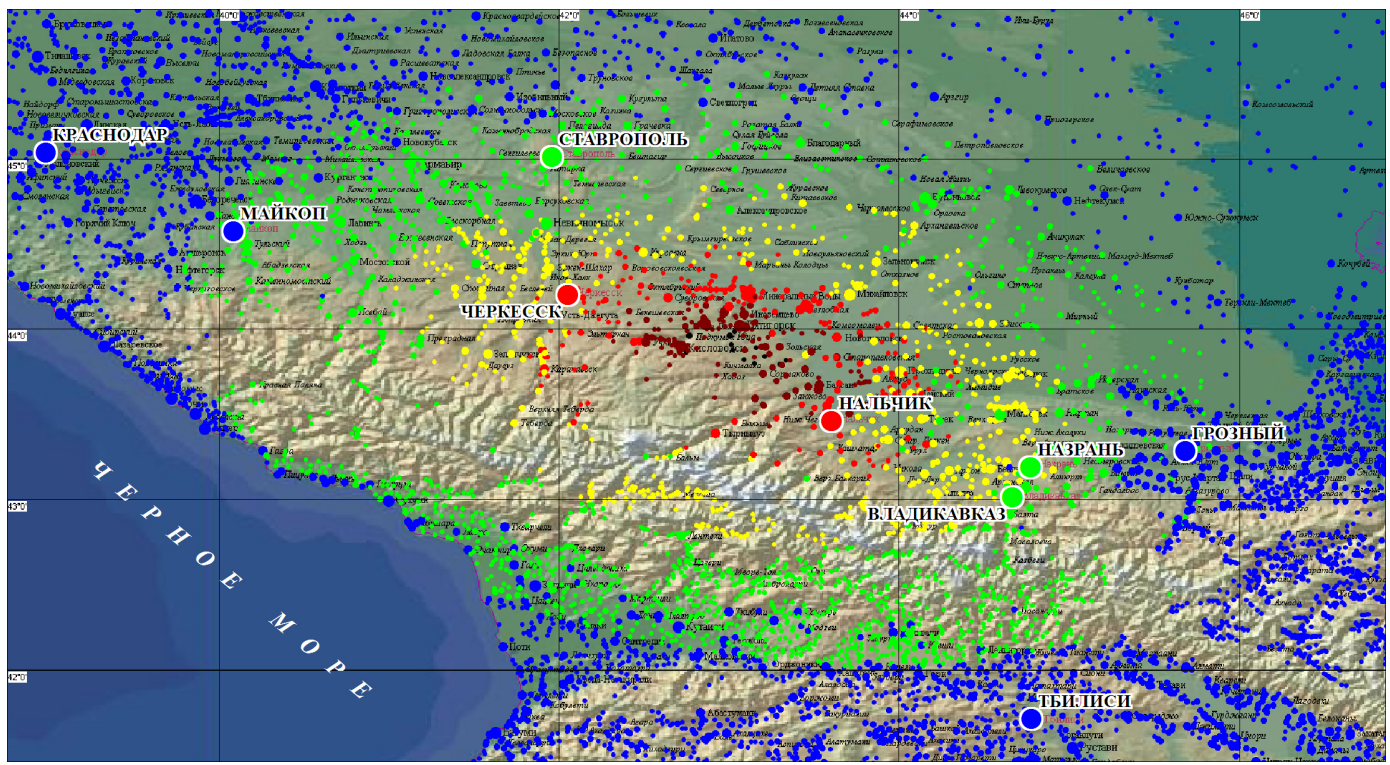

Fig. 5. Simulation of expected damage due to scenario event no. 1. Distribution of average damage states to building stock in settlements: black colour - total collapse, brown - partial collapse, red - heavy damage, yellow - moderate, green - slight, blue - no damage. 
Table 5. Expected damage to building stock in settlements of the Stavropol area.

\begin{tabular}{|c|c|c|c|c|c|c|c|c|c|c|c|c|c|c|}
\hline \multirow{2}{*}{$\begin{array}{l}\text { Settlement } \\
\text { name }\end{array}$} & \multicolumn{7}{|c|}{$\begin{array}{l}\text { Scenario } \\
\text { event no. } 1\end{array}$} & \multicolumn{7}{|c|}{$\begin{array}{c}\text { Scenario } \\
\text { event no. } 4\end{array}$} \\
\hline & $\Delta, \mathrm{km}$ & \multicolumn{5}{|c|}{ Percent of buildings with different $d$} & $d_{\mathrm{av}}$ & $\Delta, \mathrm{km}$ & \multicolumn{5}{|c|}{ Percent of buildings with different $d$} & $d_{\mathrm{av}}$ \\
\hline Essentuki & 36 & 4 & 10 & 18 & 27 & 38 & 4 & 52 & 10 & 19 & 27 & 24 & 14 & 3 \\
\hline Pyatigorsk & 30 & 4 & 10 & 18 & 27 & 38 & 4 & 61 & 13 & 23 & 28 & 20 & 8 & 3 \\
\hline Cherkessk & 98 & 15 & 31 & 30 & 16 & 5 & 3 & 64 & 8 & 26 & 32 & 22 & 9 & 3 \\
\hline
\end{tabular}

Table 6. Possible consequences of chemical hazmat release for two scenario accidents: most dangerous and probable events.

\begin{tabular}{lll}
\hline Facility & Sochi Fishery Plant & Adler Water Supply System \\
\hline Type and amount of chemical hazmat & Ammonia, 2 tons & Chlorine, 0.3 tons \\
Estimated frequency of accidents, /year & $1 \times 10^{-5}$ & $1 \times 10^{-4}$ \\
Size of the contaminated area, $\mathrm{km}^{2}$ & 0.82 & 0.3 \\
Expected fatalities, persons & 28 & 2 \\
Expected casualties, persons & 224 & 16 \\
Expected damage, thousands rubles & 120000 & 321 \\
\hline
\end{tabular}

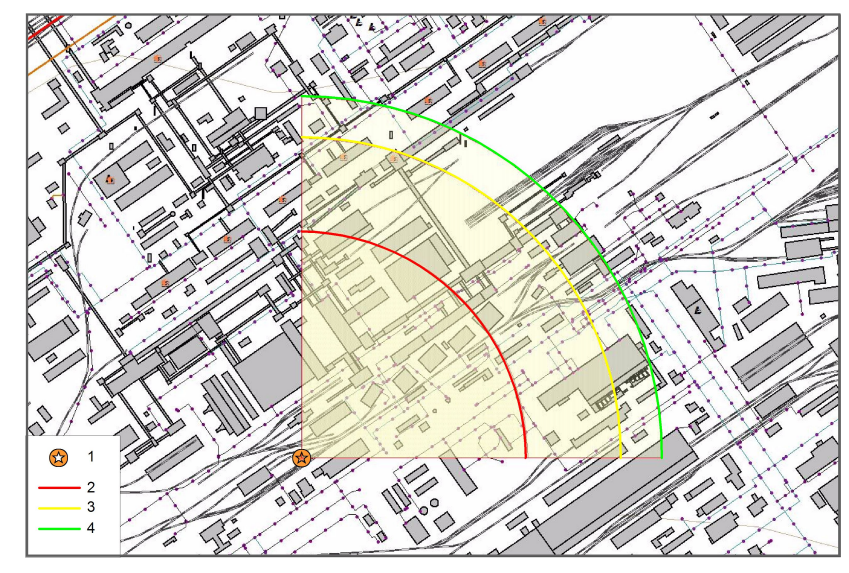

Fig. 6. Simulation of possible contaminated zones in the case of an accident with chemical material release: 1 - source of release of 3.0 tons liquid chlorine; 2 - after $1 \mathrm{~h} ; 3$ - after $3 \mathrm{~h}$ and 4 - after $4 \mathrm{~h}$.

By different colours the contaminated zones' boundaries are shown for different time intervals from $1 \mathrm{~h}$ up to $4 \mathrm{~h}$. Table 6 shows the results of possible consequences simulation of chemical hazmat release for two most dangerous and probable events in the case of strong earthquake in Sochi City. Figure 7 shows the results of individual risk estimation for oil reservoirs storage (tank farm) and pump station of oil pipe line system belonging to TRANSNEFT JSC for the case of technological accidents triggered by earthquakes.

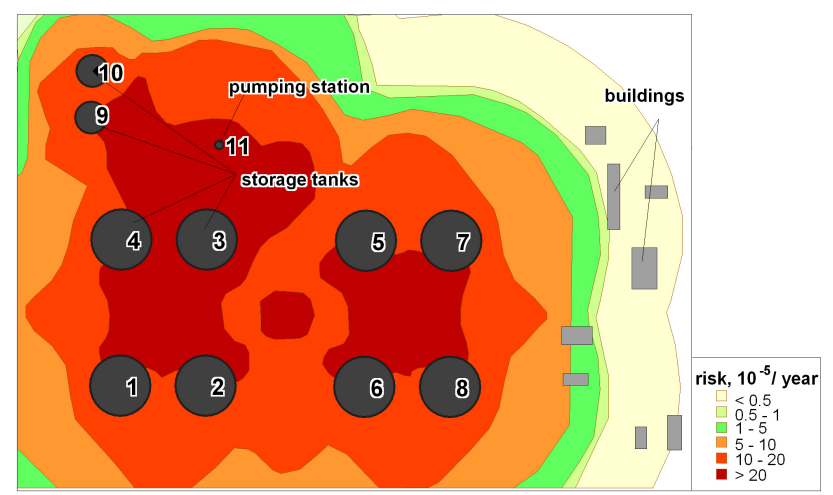

Fig. 7. Zoning of the oil storage tank farm's territory according to the level of individual risk.

\section{Conclusions}

The present paper describes the methodological procedure used for the assessment of seismic risk using special GIS environment.

Examples of seismic risk assessment at different levels (urban and facility level), as well as scenario earthquake consequences' assessment taking into account possible secondary accidents at fire, explosion and chemical hazardous facilities, are given. 
The estimations of individual seismic risk obtained are used by EMERCOM of the Russian Federation, as well as by other federal and local authorities, for planning and implementing preventive measures, aimed at saving lives and protecting property against future disastrous events. The results also allow to develop effective emergency response plans taking into account possible scenario events.

Taking into consideration the size of the oil pipe line systems located in the highly active seismic zones, the results of seismic risk computation are used by TRANSNEFT JSC.

Acknowledgements. The work was funded by the Ministry of Education and Science of the Russian Federation. The authors thank their colleagues for continuing support, discussion of different steps of loss estimation procedures and uncertainties introduced by databases and mathematical models. Special thanks are to the staff of Extreme Situations Research Center for their contribution to GIS environment development at different levels.

Edited by: E. Petrova

Reviewed by: F. Sabetta and another anonymous referee

\section{References}

Boissonnade, A. C. and Shah, H. C.:. Seismic Vulnerability and Insurance Studies, The Geneva Papers, 9, 223-254, 1984.

Bonnin, J. and Frolova, N.: Near Real-Time Loss Assessment Due To Strong Earthquakes: The State of The Art, Proc. XXIXth General Assembly of European Seismological Commission (ESC2004), Potsdam, Germany, 2004.

Bonnin, J., Frolova, N., Kozlov, M., Larionov, V., Sushchev, S., and Ugarov, A.: Experience of "Extremum" System Application for Operative Earthquake Loss Assessment, Proc. 28th General ESC Assembly, Genoa, Italy, 2002.

Dolce, M., Kappos, A., Zuccaro, G., and Coburn, A. W.: Report of the EAEE Working Group 3: Vulnerability and Risk Analysis, Proceedings of 10th European Conference on Earthquake Eingineering, 3049-3077, 1995.

Fournier d'Albe: An Approach to Earthquake Risk Management, Eng. Struct., 4, 145-152, 1982.

Fournier d'Albe: The Assessment of Seismic Risk, Proceedings of UNDRO/UNESCO/USSR Seminar on Earthquake Prediction and Mitigation of Earthquake Losses, Dushanbe, UNDRO, Geneva, 1986.

Frolova, N., Kozlov, M., Larionov, V., Suschev, S., and Ugarov, A.: Extremum System for Earthquake Risk And Loss Assessment, Proc. of SE-40EEE, Skopje-Ohrid, Macedonia, 2003.

Frolova, N., Larionov, V., and Bonnin, J.: Simulation-based information systems for multi-hazard risk and near real time loss estimations due to strong earthquakes, Proc. TIEMS2007 Conference, Trogir, Croatia, 2007.
Frolova, N., Larionov, V., and Bonnin, J.: Earthquake Casualties Estimations in Emergency Mode, in: Human Casualties in Earthquakes: Progress in Modelling and Mitigation, Adv. Nat. Technol. Hazards Res., Springer, 29, 107-123, 2011.

Karnik, V.: Existing Recommendations and Definitions on Disaster Insurance, The Geneva Papers, 9, 3-7, 1984.

Karnik, V. and Algermissen, S. T.: Seismig Zoning: The Assessment and Mitigation of Earthquake Risk, UNESCO, Paris, 1147, 1978.

Larionov, V. and Frolova, N: Peculiarities of seismic vulnerability estimations. In: Natural Hazards in Russia, volume 6: Natural Risks Assessment and Management, Publishing House "Kruk", Moscow, 120-131, 2003a (in Russian).

Larionov, V., Suschev, S., Ugarov, A., and Frolova, N.: Seismic risk assessment with GIS-technology application, in: Natural Hazards in Russia, volume 6: Natural Risks Assessment and Management, Publishing House "Kruk", Moscow, 209-231, 2003b (in Russian).

Methods of earthquake consequences forecast: Moscow, VNII GOChS, Extreme Situations Research Center, Seismological Center of IGE RAS, 2000, 27 pp., 2000 (in Russian).

Methods of integrated natural and technological risk assessment: Moscow, VNII GOChS, Extreme Situations Research Center, Seismological Center of IGE RAS, 2002, 35 pp., 2002 (in Russian).

Mitigating Natural Disasters: Phenomena, Effects and Options, A Manual for Policy Makers and Planners, UNDRO, New York, UN, 164 pp., 1991.

Ranguelov, R.: Natural Hazards - Nonlinearities and Assessment, Acad. House M. Drinov, Sofia, 237 pp., 2011.

Risk Assessment and Mapping Guidelines for Disaster Management: available at: http://register.consilium.europa.eu/pdf/en/10/ st17/st17833.en10.pdf, 2010.

Shebalin, N., Gekhman, A., and Shestoperov, G.: Development of improved version of seismic intensity scale (MMSK-86) on the bases of MSK-64 scale and scale of Joint Council on Seismology and Earthquake Engineering - 73, Report on scientific research study within the Federal Program 0.74.03, number of state registration 01814003271, Joint Council on Seismology and Earthquake Engineering, Academy of Sciences of the USSR, Moscow, 1986 (in Russian).

Sobolev, G., Rogozhin, E., Bogachkin, B., Ioganson, L., Nechaev, Yu., Reisner, G., and Sidorin, A.: Development of seismogenic zones map using over regional method. Institute Physics of the Earth Report "Compiling the map of detailed seismic zoning of the Stavropol region territory", vol. 3, Moscow, 1996 (in Russian).

UNISDR Terminology on Disaster Risk Reduction: available at: http://www.unisdr.org/eng/terminology/ UNISDR-terminology-2009-eng.pdf, 2009. 